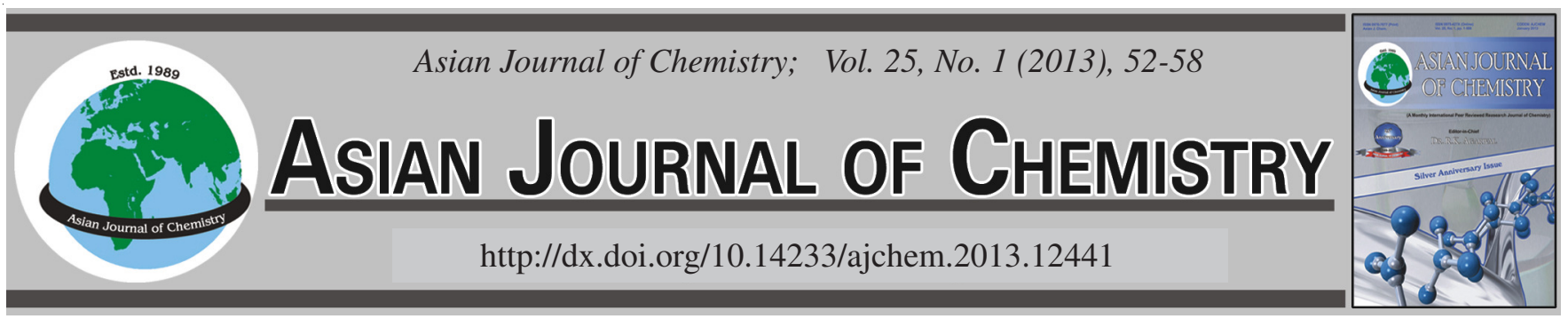

\title{
In vitro Antioxidant Activity and Scavenging Effects of Some Synthesized 4'-Aminochalcones
}

\author{
Y. RaJendra Prasad ${ }^{1}$, V. JHANSI RANi ${ }^{1,2}$ and A. SRINIVASa RaO ${ }^{3, *}$
}

${ }^{1}$ Department of Pharmaceutical Chemistry, University College of Pharmaceutical Sciences, Andhra University, Visakhapatnam-530 003, India ${ }^{2}$ Department of Pharmacology, University College of Pharmaceutical Sciences Andhra University, Visakhapatnam-530 003, India ${ }^{3}$ Department of Pharmaceutical Chemistry, Shri Vishnu College of Pharmacy, Vishnupur, Bhimavaram-534 202, India

*Corresponding author: Fax: +91 8816 250863; E-mail: atlas1772@rediffmail.com

\begin{abstract}
A new series of substituted 4'-aminochalcones were synthesized by Claisen-Schmidt condensation of 4-aminoacetophenone with various substituted aromatic/heteroaromatic aldehydes. The antioxidant activity for all these compounds were studied on various reactive oxygen species assays containing superoxide anion, hydroxyl radical, ABTS cation radical scavenging and inhibition of lipid peroxidation assays. Chalcones 9 and 10 made up of 3,4,5-trimethoxyphenyl and 4-dimethylaminophenyl moieties as ring-B of chalcones respectively exhibited maximum activity in various antioxidant assays, which may be due to the free radical scavenging activity. The present study revealed that an electron releasing group at position 4 of the ring B of chalcone is essential for exhibiting significant antioxidant activity.
\end{abstract}

Key Words: 4'-Aminochalcones, Lipid peroxidation, Antioxidant activity, Scavenging effects.

\section{INTRODUCTION}

Several diseases caused by free radicals have been reported such as atherosclerosis, cancer, liver cirrhosis, cancer, aging, diabetes, etc. ${ }^{1}$ and the scavenging effects of these free radicals by the chemical compounds have great potential in ameliorating these disease progresses ${ }^{2}$. Because of the human body has an inherent mechanism to reduce free radical induced injury by endogenous enzymes such as superoxide dismutase, glutathione peroxidase, catalase and others such as ascorbic acid (vitamin C) etc. When compared to the damage produced to the body, these protective mechanisms are sometimes found not to be sufficient. Hence, the exogenous antioxidants are required to overcome the injuries produced by free radicals and lipid peroxidation.

Flavonoids widely distributed in nature, possessing high degree of antioxidant activity are found to be useful in this type of injuries ${ }^{3}$. An antioxidant which is capable of attacking the reactive oxygen species along with inhibiting lipid peroxidation process is of immense value in the effective therapy of various diseases resulting from oxidative damage, e.g. curcumin, a popular and natural antioxidant ${ }^{4}$. As chalcones (1,3-diaryl-2-propen-1-one, Fig. 1) are the precursors for flavonoids, it has been hypothetized to have antioxidant activity. The role of the chalcones as antipromoters becomes evident. Isoliquiritigenin (Fig. 2), a trihydroxy chalcone has been shown to inhibit TPA induced tumor promotion in mice ${ }^{5}$.
Chalcones are also reported to display a number of interesting biological activities such as antimalarial ${ }^{6}$, antimicrobial ${ }^{7}$, antitubercular $^{8}$, antiviral ${ }^{9}$, antileishmanial ${ }^{10}$, cytotoxic $^{11}$, anticancer $^{12}$, antioxidant ${ }^{13}$, antiinflammatory ${ }^{14}$, analgesic ${ }^{15}$, antihyperglycemic ${ }^{16}$, antimutagenic ${ }^{17}$ and phosphodiesterase inhibitory activities ${ }^{18}$. The discovery of this class of compounds provides an outstanding case history of modern drug development and also points out the unpredictability of biological activity from structural modification of a prototype leading molecule. As part of our continuing efforts in this area, a series of some new 4'-aminochalcones have been synthesized and evaluated for their antiinflammatory and analgesic activities ${ }^{19,20}$. The present paper was aimed to investigate the free radical scavenging and antioxidant activities of synthesized 4'-aminochalcones.<smiles>[R]c1ccc(C(=O)/C=C/c2ccccc2)cc1</smiles>

Fig. 1.<smiles>O=C(C=Cc1ccc(O)cc1)c1ccc(O)cc1O</smiles>

Fig. 2. 


\section{EXPERIMENTAL}

Melting points were determined with an electrothermal capillary melting point apparatus and are reported uncorrected. Infrared (IR) spectra were recorded on a Perkin-Elmer BXF1 FT-IR spectrophotometer using $\mathrm{KBr}$ disc and the values are expressed in $\mathrm{cm}^{-1} .{ }^{1} \mathrm{H}$ and ${ }^{13} \mathrm{C}$ nuclear magnetic resonance (NMR) spectra were recorded on a Bruker AMX 400 and 100 spectrophotometer respectively with tetramethylsilane (TMS) as internal standard using $\mathrm{CDCl}_{3}$ as solvent and the values are expressed in $\delta$ ppm. Mass [EI-MS $(70 \mathrm{eV})$ ] spectra were recorded on Agilent 1100 EI-Mass spectrophotometer. The elemental analyses of the synthesized compounds were recorded on Carlo Erba 1108 elemental analyzer and were within $\pm 0.4 \%$ of the theoretical values, unless otherwise noted. Analytical TLC was performed on Silica Gel $\mathrm{F}_{254}$ plates (Merck) with visualization by UV (254 $\mathrm{nm}$ ) chamber with protective filters. 4-Aminoacetophenone, substituted aromatic and/or heteroaromatic aldehydes were purchased from E. Merck (India) Ltd., Mumbai, India. All other materials used were of analytical reagent grade.

Chalcones (1 to 16) were obtained as following the procedure given under Scheme-I by the reaction of 4aminoacetophenone with various substituted aromatic/ heteroaromatic aldehydes in the presence of aqueous alkali. The absorption bands in IR spectra for primary amino group (3350-3300 $\left.\mathrm{cm}^{-1}\right)$, carbonyl group (1650-1600 $\mathrm{cm}^{-1}$ ) and olefinic group (1600-1550 $\left.\mathrm{cm}^{-1}\right)$ indicated the formation of the chalcones. The ${ }^{1} \mathrm{H}$ NMR spectra $\left(400 \mathrm{MHz}, \mathrm{CDCl}_{3}\right)$ showed a broad singlet between $\delta 4.15-4.22$ for $\mathrm{NH}_{2}$ group, two doublets in between $\delta 6.50-7.50$ for olefinic protons $(\mathrm{J} \cong 16.0$ $\mathrm{Hz}$ ) indicates that E-geometrical isomers and the aromatic protons appeared in between $\delta 6.00-9.00$. In the ${ }^{13} \mathrm{C} \mathrm{NMR}$ spectrum exhibited characteristic peaks between $\delta$ 190-180 for carbonyl group, $\delta$ 145-135 and $\delta$ 125-120 for olefinic carbons confirming the chalcones structure. The mass spectra showed the corresponding molecular ion peak $\left[\mathrm{M}^{+}\right]$as the base peak and the fragmentation patterns was characteristic of respective chalcones. The elemental analyses of all the newly synthesized compounds confirmed their structures.

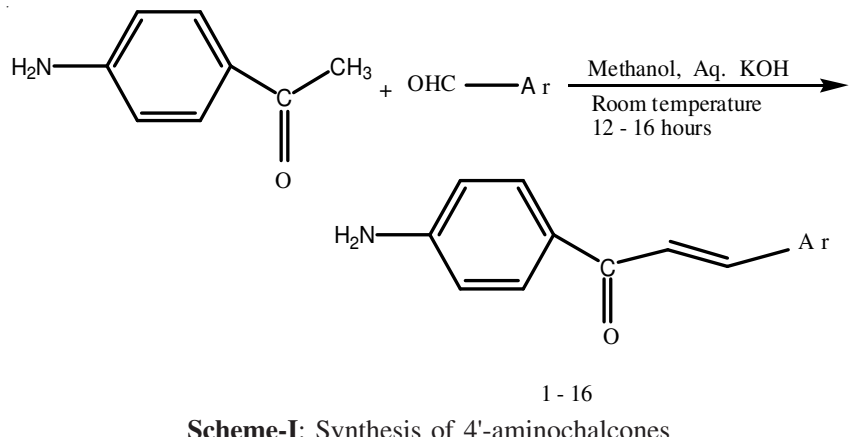

Synthesis of chalcones, (1-16) ${ }^{7}$ : Potassium hydroxide (10\% aqueous solution, $1 \mathrm{~mL}$ ) was added to a stirred solution of 4-aminoacetophenone ( $1 \mathrm{mmol})$ and a substituted aromatic/ heteroaromatic aldehyde $(1 \mathrm{mmol})$ in methanol $(10 \mathrm{~mL})$ (Scheme-I and Table-1). Stirring was carried out for at least 12-16 $\mathrm{h}$ at room temperature and each hour the reaction mixture was analyzed by TLC. Then the reaction mixture was poured into ice water, if necessary acidified with dil. $\mathrm{HCl}$ and extracted with ethyl acetate $(3 \times 50 \mathrm{~mL})$. The combined organic layer was washed with water, dried and concentrated in vacuиo. The residue was purified on a column of silica gel using hexane-ethyl acetate $(4: 1)$ as eluant affording pure chalcones 1-16 in 37 to $81 \%$ yield.

\begin{tabular}{clcl}
\multicolumn{4}{c}{ TABLE-1 } \\
& \multicolumn{4}{c}{ SUBSTITUTED 4'-AMINOCHALCONES } \\
\hline Comp. & \multicolumn{1}{c}{ Ar } & Comp. & \multicolumn{1}{c}{ Ar } \\
\hline $\mathbf{1}$ & 3-Bromophenyl & $\mathbf{9}$ & 3,4,5-Trimethoxyphenyl \\
$\mathbf{2}$ & 4-Methylphenyl & $\mathbf{1 0}$ & 4-Dimethylaminophenyl \\
$\mathbf{3}$ & 2-Chlorophenyl & $\mathbf{1 1}$ & 9-Anthracenyl \\
$\mathbf{4}$ & 4-Chlorophenyl & $\mathbf{1 2}$ & 4-Nitrophenyl \\
$\mathbf{5}$ & 2,4-Dichlorophenyl & $\mathbf{1 3}$ & 3-Pyridinyl \\
$\mathbf{6}$ & 4-Fluorophenyl & $\mathbf{1 4}$ & 2-Pyridinyl \\
$\mathbf{7}$ & 4-Methoxyphenyl & $\mathbf{1 5}$ & 4-Pyridinyl \\
$\mathbf{8}$ & 3,4-Dimethoxyphenyl & $\mathbf{1 6}$ & 2-Quinolinyl \\
\hline
\end{tabular}

1-(4'-Aminophenyl)-3-(3"-bromophenyl)-2-propen-1one (1): Orange crystals, yield $81 \%$, m.p. $168-171^{\circ} \mathrm{C}$. IR $\left(\mathrm{KBr}, \mathrm{v}_{\max }, \mathrm{cm}^{-1}\right): 3414,3326,1652,1626,1304,1177 .{ }^{1} \mathrm{H}$ NMR $\left(\mathrm{CDCl}_{3}, 400 \mathrm{MHz}, \delta \mathrm{ppm}\right): 4.20\left(2 \mathrm{H}\right.$, br s, $\left.\mathrm{NH}_{2}\right), 6.72$ $(1 \mathrm{H}, \mathrm{d}, J=16.0 \mathrm{~Hz}, \mathrm{CO}-\mathrm{CH}=), 7.27\left(2 \mathrm{H}, \mathrm{d}, J=10.2 \mathrm{~Hz}, \mathrm{C}-3{ }^{\prime}\right.$ and 5'-H), 7.57-7.49 (3H, m, C-4",5" and 6"-H), $7.70(1 \mathrm{H}, \mathrm{d}$, $J=16.0 \mathrm{~Hz}, \mathrm{Ar}-\mathrm{CH}=), 7.80(1 \mathrm{H}, \mathrm{s}, \mathrm{C}-2 "-\mathrm{H}), 7.95(2 \mathrm{H}, \mathrm{d}, J=$ $10.0 \mathrm{~Hz}, \mathrm{C}-2^{\prime}$ and $\left.6^{\prime}-\mathrm{H}\right) .{ }^{13} \mathrm{C} \mathrm{NMR}\left(\mathrm{CDCl}_{3}, 100 \mathrm{MHz}, \delta \mathrm{ppm}\right)$ : $187.59,151.31,141.26,137.63,132.79,131.19,130.65$, 130.39, 128.43, 127.11, 123.50, 123.06 and 114.01. EI-MS, $m / z: 302\left[\{\mathrm{M}+\mathrm{H}\}^{+}\right]$. Anal. calcd. for $\mathrm{C}_{15} \mathrm{H}_{12} \mathrm{NOBr}$ : C, 59.66; H, 4.00. Found: C, 59.60; H, 3.97.

1-(4'-Aminophenyl)-3-(4"'-methylphenyl)-2-propen-1one (2): Yellow crystals, yield $65.78 \%$, m.p. $162-165^{\circ} \mathrm{C}$. IR $\left(\mathrm{KBr}, \mathrm{cm}^{-1}\right): 3471,3348,1628$ and $1602 .{ }^{1} \mathrm{H} \mathrm{NMR}\left(\mathrm{CDCl}_{3}\right.$, $400 \mathrm{MHz}, \delta \mathrm{ppm}): 2.42\left(3 \mathrm{H}, \mathrm{s}, \mathrm{C}-4 "-\mathrm{CH}_{3}\right), 4.20(2 \mathrm{H}$, br s, $\left.\mathrm{NH}_{2}\right), 6.81\left(2 \mathrm{H}, \mathrm{d}, J=8.0 \mathrm{~Hz}, \mathrm{C}-3^{\prime}\right.$ and $\left.5^{\prime}-\mathrm{H}\right), 7.05(1 \mathrm{H}, \mathrm{d}, J=$ $15.8 \mathrm{~Hz}, \mathrm{CO}-\mathrm{CH}=), 7.23(2 \mathrm{H}, \mathrm{d}, J=7.6 \mathrm{~Hz}, \mathrm{C}-2 "$ and 6"-H), $7.53(2 \mathrm{H}, \mathrm{d}, J=8.0 \mathrm{~Hz}, \mathrm{C}-3 "$ and 5"-H), $7.73(1 \mathrm{H}, \mathrm{d}, J=16.0$ $\mathrm{Hz}, \mathrm{Ar}-\mathrm{CH}=), 8.03\left(2 \mathrm{H}, \mathrm{d}, J=10.0 \mathrm{~Hz}, \mathrm{C}-2^{\prime}\right.$ and $\left.6^{\prime}-\mathrm{H}\right) .{ }^{13} \mathrm{C}$ $\mathrm{NMR}\left(\mathrm{CDCl}_{3}, 100 \mathrm{MHz}, \delta \mathrm{ppm}\right): 191.75,159.05,148.45$, $142.81,139.49,136.23,134.06,131.17,130.29,129.68$, 121.48 and 63.54. EI-MS, $m / z: 238\left[\{\mathrm{M}+\mathrm{H}\}^{+}\right]$. Anal. calcd. for $\mathrm{C}_{16} \mathrm{H}_{15} \mathrm{NO}$ : C, 81.08; H, 6.32. Found: C, 81.01; H, 6.32.

1-(4'-Aminophenyl)-3-(2"'-chlorophenyl)-2-propen-1one (3): Yellow crystals, yield $79.64 \%$, m.p. $108-111^{\circ} \mathrm{C}$. IR $\left(\mathrm{KBr}, \mathrm{v}_{\max }, \mathrm{cm}^{-1}\right): 3384,3332,1647,1607,1340$ and $1178 .{ }^{1} \mathrm{H}$ $\mathrm{NMR}\left(\mathrm{CDCl}_{3}, 400 \mathrm{MHz}, \delta \mathrm{ppm}\right): 4.09\left(2 \mathrm{H}\right.$, br s, $\left.\mathrm{NH}_{2}\right), 6.62$ $\left(2 \mathrm{H}, \mathrm{d}, J=8.8 \mathrm{~Hz}, \mathrm{C}-3^{\prime}\right.$ and $\left.5^{\prime}-\mathrm{H}\right), 7.26-7.21$ (2H, m, C-4" and 5"-H), 7.37-7.34 (1H, m, C-6"-H), $7.41(1 \mathrm{H}, \mathrm{d}, J=16.0 \mathrm{~Hz}$, $\mathrm{CO}-\mathrm{CH}=), 7.67-7.64(1 \mathrm{H}, \mathrm{m}, \mathrm{C}-3 "-\mathrm{H}), 7.85(2 \mathrm{H}, \mathrm{d}, J=8.4$ Hz, C-2' and 6'-H), 8.05 (1H, d, J=15.8 Hz, Ar-CH=). EI-MS, $m / z: 258\left[\{\mathrm{M}+\mathrm{H}\}^{+}\right]$. Anal. calcd. for $\mathrm{C}_{15} \mathrm{H}_{12} \mathrm{NOCl}$ : C, 69.97; H, 4.70. Found: C, 69.90; H, 4.66.

1-(4'-Aminophenyl)-3-(4"'-chlorophenyl)-2-propen-1one (4): Orange crystals, yield $66 \%$, m.p. $158-161^{\circ} \mathrm{C}$. IR $\left(\mathrm{KBr}, \mathrm{v}_{\max }, \mathrm{cm}^{-1}\right): 3459,3341,1645,1629,1346$ and $1176.1 \mathrm{H}$ NMR $\left(\mathrm{CDCl}_{3}, 400 \mathrm{MHz}, \delta \mathrm{ppm}\right): 4.17$ (2H, br s, $\left.\mathrm{NH}_{2}\right), 6.72$ $\left(2 \mathrm{H}, \mathrm{d}, J=10.0 \mathrm{~Hz}, \mathrm{C}-3^{\prime}\right.$ and $\left.5^{\prime}-\mathrm{H}\right), 7.22(1 \mathrm{H}, \mathrm{d}, J=16.0 \mathrm{~Hz}$, 
$\mathrm{CO}-\mathrm{CH}=), 7.38(2 \mathrm{H}, \mathrm{d}, J=8.0 \mathrm{~Hz}, \mathrm{C}-2 "$ and 6"-H), $7.73(2 \mathrm{H}$, $\mathrm{d}, J=8.8 \mathrm{~Hz}, \mathrm{C}-3 "$ and 5"-H ), $7.93\left(2 \mathrm{H}, \mathrm{d}, J=10.0 \mathrm{~Hz}, \mathrm{C}-2^{\prime}\right.$ and 6'-H), $8.02(1 \mathrm{H}, \mathrm{d}, J=15.8 \mathrm{~Hz}, \mathrm{Ar}-\mathrm{CH}=)$. EI-MS, $m / z$ : $258\left[\{\mathrm{M}+\mathrm{H}\}^{+}\right]$. Anal. calcd. for $\mathrm{C}_{15} \mathrm{H}_{12} \mathrm{NOCl}$ : C, 69.97; H, 4.70. Found: C, 69.90; H, 4.66.

1-(4'-Aminophenyl)-3-(2",4"-dichlorophenyl)-2propen-1-one (5): Creamy yellow crystals, yield $87.73 \%$, m.p. $178-180^{\circ} \mathrm{C}$. IR $\left(\mathrm{KBr}, v_{\max }, \mathrm{cm}^{-1}\right): 3436,3362,1651,1609$, 1343 and 1180. ${ }^{1} \mathrm{H}$ NMR $\left(\mathrm{CDCl}_{3}, 400 \mathrm{MHz}, \delta \mathrm{ppm}\right): 4.20$ $\left(2 \mathrm{H}\right.$, br s, $\left.\mathrm{NH}_{2}\right), 6.71(1 \mathrm{H}, \mathrm{d}, J=15.8 \mathrm{~Hz}, \mathrm{CO}-\mathrm{CH}=), 7.31$ $(1 \mathrm{H}, \mathrm{d}, J=8.6 \mathrm{~Hz}, \mathrm{C}-6 "-\mathrm{H}), 7.47\left(2 \mathrm{H}, \mathrm{d}, J=10.0 \mathrm{~Hz}, \mathrm{C}-3{ }^{\prime}\right.$ and 5'-H), $7.56(1 \mathrm{H}, \mathrm{d}, J=8.2 \mathrm{~Hz}, \mathrm{C}-5 "-\mathrm{H}), 7.70$ (1H, m, C-3"-H), $7.93(1 \mathrm{H}, \mathrm{d}, J=16.0 \mathrm{~Hz}, \mathrm{Ar}-\mathrm{CH}=), 8.06(2 \mathrm{H}, \mathrm{d}, J=8.0 \mathrm{~Hz}$, C-2' and 6'-H). EI-MS, m/z: $292\left(\mathrm{M}^{+}\right)$. Anal. calcd. for $\mathrm{C}_{15} \mathrm{H}_{11} \mathrm{NOCl}_{2}$ : C, 61.70; H, 3.79. Found: C, 61.64; H, 3.77.

1-(4'-Aminophenyl)-3-(4"'-fluorophenyl)-2-propen-1one (6): Orange crystals, yield $66 \%$, m.p. $140-143{ }^{\circ} \mathrm{C}$. IR $\left(\mathrm{KBr}, \mathrm{v}_{\max }, \mathrm{cm}^{-1}\right): 3460,3340,1628,1603,1345$ and $1223 .{ }^{1} \mathrm{H}$ NMR $\left(\mathrm{CDCl}_{3}, 400 \mathrm{MHz}, \delta \mathrm{ppm}\right): 4.20\left(2 \mathrm{H}\right.$, br s, $\left.\mathrm{NH}_{2}\right), 6.62$ $\left(2 \mathrm{H}, \mathrm{d}, J=8.4 \mathrm{~Hz}, \mathrm{C}-3^{\prime}\right.$ and $\left.5^{\prime}-\mathrm{H}\right), 7.03(2 \mathrm{H}, \mathrm{d}, J=8.8 \mathrm{~Hz}$, C-2" and 6"-H), $7.38(1 \mathrm{H}, \mathrm{d}, J=16.0 \mathrm{~Hz}, \mathrm{CO}-\mathrm{CH}=), 7.53$ $(2 \mathrm{H}, \mathrm{d}, J=10.0 \mathrm{~Hz}, \mathrm{C}-3 "$ and $5 "-\mathrm{H}), 7.66(1 \mathrm{H}, \mathrm{d}, J=16.0 \mathrm{~Hz}$, Ar- $\mathrm{CH}=), 7.85\left(2 \mathrm{H}, \mathrm{d}, J=8.2 \mathrm{~Hz}, \mathrm{C}-2{ }^{\prime}\right.$ and 6'-H). EI-MS, $m / z: 242\left[\{\mathrm{M}+\mathrm{H}\}^{+}\right]$. Anal. calcd. for $\mathrm{C}_{15} \mathrm{H}_{12} \mathrm{NOF}: \mathrm{C}, 74.76 ; \mathrm{H}$, 5.01. Found: C, 74.68; H, 4.97.

1-(4'-Aminophenyl)-3-(4"'-methoxyphenyl)-2-propen1-one (7): Yellow crystals, yield $64.87 \%$, m.p. $108-111^{\circ} \mathrm{C}$. IR (KBr, $\left.v_{\max }, \mathrm{cm}^{-1}\right): 3467,3329,1631,1598,1342$ and 1230. ${ }^{1} \mathrm{H} \mathrm{NMR}\left(\mathrm{CDCl}_{3}, 400 \mathrm{MHz}, \delta \mathrm{ppm}\right): 3.85\left(3 \mathrm{H}, \mathrm{s}, \mathrm{C}-4\right.$ "- $\left.-\mathrm{OCH}_{3}\right)$, $4.20\left(2 \mathrm{H}\right.$, br s, $\left.\mathrm{NH}_{2}\right), 6.71(1 \mathrm{H}, \mathrm{d}, J=16.0 \mathrm{~Hz}, \mathrm{CO}-\mathrm{CH}=), 6.93$ $\left(2 \mathrm{H}, \mathrm{d}, J=10.0 \mathrm{~Hz}, \mathrm{C}-3^{\prime}\right.$ and $\left.5^{\prime}-\mathrm{H}\right), 7.43(2 \mathrm{H}, \mathrm{d}, J=9.0 \mathrm{~Hz}$, C-3" and 5"-H), $7.60(2 \mathrm{H}, \mathrm{d}, J=8.8 \mathrm{~Hz}, \mathrm{C}-2$ " and 6"-H), 7.76 $(1 \mathrm{H}, \mathrm{d}, J=16.0 \mathrm{~Hz}, \mathrm{Ar}-\mathrm{CH}=), 7.94\left(2 \mathrm{H}, \mathrm{d}, J=9.6 \mathrm{~Hz}, \mathrm{C}-2^{\prime}\right.$ and 6'-H). EI-MS, $m / z$ : $253\left(\mathrm{M}^{+}\right)$. Anal. calcd. for $\mathrm{C}_{16} \mathrm{H}_{15} \mathrm{NO}_{2}$ : C, 75.96; H, 5.97. Found: C, 75.88; H, 5.92.

1-(4'-Aminophenyl)-3-(3",4"-dimethoxyphenyl)-2propen-1-one (8): Orange crystals, yield $72.43 \%$, m.p. 146$149{ }^{\circ} \mathrm{C}$. IR ( $\left.\mathrm{KBr}, v_{\max }, \mathrm{cm}^{-1}\right): 3445,3351,1641,1597,1317$ and 1260. ${ }^{1} \mathrm{H} \mathrm{NMR}\left(\mathrm{CDCl}_{3}, 400 \mathrm{MHz}, \delta \mathrm{ppm}\right): 3.84(3 \mathrm{H}, \mathrm{s}$, C-3"- $\left.\mathrm{OCH}_{3}\right), 3.86\left(3 \mathrm{H}, \mathrm{s}, \mathrm{C}-4\right.$ "- $\left.\mathrm{OCH}_{3}\right), 4.21\left(2 \mathrm{H}\right.$, br s, $\left.\mathrm{NH}_{2}\right)$, $6.71\left(2 \mathrm{H}, \mathrm{d}, J=8.0 \mathrm{~Hz}, \mathrm{C}-3^{\prime}\right.$ and $\left.5^{\prime}-\mathrm{H}\right), 7.13-6.79(3 \mathrm{H}, \mathrm{m}$, C-2",5" and 6"-H), $7.30(1 \mathrm{H}, \mathrm{d}, J=15.8 \mathrm{~Hz}, \mathrm{CO}-\mathrm{CH}=), 7.64$ $(1 \mathrm{H}, \mathrm{d}, J=15.8 \mathrm{~Hz}, \mathrm{Ar}-\mathrm{CH}=), 7.84\left(2 \mathrm{H}, \mathrm{d}, J=8.4 \mathrm{~Hz}, \mathrm{C}-2^{\prime}\right.$ and 6'-H). EI-MS, $m / z$ : $283\left(\mathrm{M}^{+}\right)$. Anal. calcd. for $\mathrm{C}_{17} \mathrm{H}_{17} \mathrm{O}_{3} \mathrm{~N}$ : C, 72.15; H, 6.03. Found: C, 72.08; H, 6.00.

1-(4'-Aminophenyl)-3-(3",4",5"-trimethoxyphenyl)-2propen-1-one (9): Yellow crystals, yield $70.55 \%$, m.p. 160$162{ }^{\circ} \mathrm{C}$. IR (KBr, $\left.v_{\max }, \mathrm{cm}^{-1}\right): 3469,3344,1630,1604,1316$ and 1219. ${ }^{1} \mathrm{H} \mathrm{NMR}\left(\mathrm{CDCl}_{3}, 400 \mathrm{MHz}, \delta \mathrm{ppm}\right): 3.90(3 \mathrm{H}, \mathrm{s}$, C-4"- $\left.\mathrm{OCH}_{3}\right), 3.93(6 \mathrm{H}, \mathrm{s}, \mathrm{C}-3$ " and 5"-OCH $), 4.19(2 \mathrm{H}$, br s, $\left.\mathrm{NH}_{2}\right), 6.71\left(2 \mathrm{H}, \mathrm{d}, J=10.0 \mathrm{~Hz}, \mathrm{C}-3^{\prime}\right.$ and $\left.5^{\prime}-\mathrm{H}\right), 6.86(2 \mathrm{H}, \mathrm{s}$, C-2" and 6"-H), 7.43 (1H, d, $J=16.0 \mathrm{~Hz}, \mathrm{CO}-\mathrm{CH}=), 7.72$ $(1 \mathrm{H}, \mathrm{d}, J=15.8 \mathrm{~Hz}, \mathrm{Ar}-\mathrm{CH}=), 7.94\left(2 \mathrm{H}, \mathrm{d}, J=8.0 \mathrm{~Hz}, \mathrm{C}-2^{\prime}\right.$ and 6'-H). EI-MS, $m / z$ : $313\left(\mathrm{M}^{+}\right)$. Anal. calcd. for $\mathrm{C}_{18} \mathrm{H}_{19} \mathrm{O}_{4} \mathrm{~N}$ : C, 69.07; H, 6.12. Found: C, 69.00; H, 6.07.

1-(4'-Aminophenyl)-3-(4"'-dimethylaminophenyl)-2propen-1-one (10): Orange red crystals, yield $66.50 \%$, m.p. $168-170{ }^{\circ} \mathrm{C}$. IR (KBr, $\left.v_{\max }, \mathrm{cm}^{-1}\right): 3474,3432,1620,1597$, 1346 and 1303. ${ }^{1} \mathrm{H}$ NMR $\left(\mathrm{CDCl}_{3}, 400 \mathrm{MHz}, \delta \mathrm{ppm}\right): 3.05$ $\left(6 \mathrm{H}, \mathrm{s}, \mathrm{C}-4 "-\mathrm{NMe}_{2}\right), 4.19\left(2 \mathrm{H}\right.$, br s, NH $\left.\mathrm{NH}_{2}\right), 6.70(2 \mathrm{H}, \mathrm{d}, J=$ $10.0 \mathrm{~Hz}, \mathrm{C}-3^{\prime}$ and 5'-H), $6.88(2 \mathrm{H}, \mathrm{d}, J=8.8 \mathrm{~Hz}, \mathrm{C}-3$ " and 5"$\mathrm{H}), 7.39(1 \mathrm{H}, \mathrm{d}, J=15.6 \mathrm{~Hz}, \mathrm{CO}-\mathrm{CH}=), 7.57(2 \mathrm{H}, \mathrm{d}, J=8.0$ $\mathrm{Hz}, \mathrm{C}-2$ " and 6"-H), 7.76 (1H, d, $J=15.4 \mathrm{~Hz}, \mathrm{Ar}-\mathrm{CH}=), 7.94$ $\left(2 \mathrm{H}, \mathrm{d}, J=8.0 \mathrm{~Hz}, \mathrm{C}-2{ }^{\prime}\right.$ and $\left.6{ }^{\prime}-\mathrm{H}\right)$. EI-MS, $m / z: 267\left[\{\mathrm{M}+\mathrm{H}\}^{+}\right]$. Anal. calcd for $\mathrm{C}_{17} \mathrm{H}_{18} \mathrm{~N}_{2} \mathrm{O}$ : C, 76.76; H, 6.82. Found: C, 76.69; H, 6.76.

1-(4'-Aminophenyl)-3-(9"'-anthracenyl)-2-propen-1one (11): Orange red crystals, yield 62.08 \%, m.p. 173-176 ${ }^{\circ} \mathrm{C}$. IR $\left(\mathrm{KBr}, v_{\max }, \mathrm{cm}^{-1}\right): 3469,3332,1650,1633$ and $1356 .{ }^{1} \mathrm{H}$ NMR $\left(\mathrm{CDCl}_{3}, 400 \mathrm{MHz}, \delta \mathrm{ppm}\right): 4.20\left(2 \mathrm{H}\right.$, br s, $\left.\mathrm{NH}_{2}\right), 7.22$ $(1 \mathrm{H}, \mathrm{d}, J=16.0 \mathrm{~Hz}, \mathrm{CO}-\mathrm{CH}=), 7.53-7.45$ (4H, m, Ar-Hanthracenyl), $7.57\left(2 \mathrm{H}, \mathrm{d}, J=8.0 \mathrm{~Hz}, \mathrm{C}-3^{\prime}\right.$ and $\left.5^{\prime}-\mathrm{H}\right), 8.03$ $(1 \mathrm{H}, \mathrm{d}, J=15.8 \mathrm{~Hz}, \mathrm{Ar}-\mathrm{CH}=)$, 8.15-8.07 (2H, m, Ar-Hanthracenyl), $8.30(2 \mathrm{H}, \mathrm{d}, J=8.2 \mathrm{~Hz}, \mathrm{C}-2$ ' and 6'-H), 8.888.45 (3H, m, Ar-H-anthracenyl). EI-MS, $m / z: 324\left[\{\mathrm{M}+\mathrm{H}\}^{+}\right]$. Anal. calcd. for $\mathrm{C}_{23} \mathrm{H}_{17} \mathrm{NO}$ : C, 85.52; H, 5.30. Found: C, 85.44; $\mathrm{H}, 5.26$.

1-(4'-Aminophenyl)-3-(4"'-nitrophenyl)-2-propen-1one (12): Orange crystals, yield $60 \%$, m.p. $182-184{ }^{\circ} \mathrm{C}$. IR $\left(\mathrm{KBr}, \mathrm{v}_{\max }, \mathrm{cm}^{-1}\right): 3484,3389,1636,1610,1506$ and $1341 .{ }^{1} \mathrm{H}$ NMR $\left(\mathrm{CDCl}_{3}, 400 \mathrm{MHz}, \delta \mathrm{ppm}\right): 4.20\left(2 \mathrm{H}\right.$, br s, $\left.\mathrm{NH}_{2}\right), 6.68$ $\left(2 \mathrm{H}, \mathrm{d}, J=10.0 \mathrm{~Hz}, \mathrm{C}-3^{\prime}\right.$ and $\left.5^{\prime}-\mathrm{H}\right), 6.72(1 \mathrm{H}, \mathrm{d}, J=16.0 \mathrm{~Hz}$, $\mathrm{CO}-\mathrm{CH}=), 7.66(2 \mathrm{H}, \mathrm{d}, J=10.0 \mathrm{~Hz}, \mathrm{C}-2 "$ and 6"-H), 7.80 $(1 \mathrm{H}, \mathrm{d}, J=16.2 \mathrm{~Hz}, \mathrm{Ar}-\mathrm{CH}=), 7.95\left(2 \mathrm{H}, \mathrm{d}, J=9.8 \mathrm{~Hz}, \mathrm{C}-2^{\prime}\right.$ and 6'-H), 8.28 (2H, d, $J=10.0 \mathrm{~Hz}, \mathrm{C}-3 "$ and 5"-H). EI-MS, $m / z: 269\left[\{\mathrm{M}+\mathrm{H}\}^{+}\right]$. Anal. calcd. for $\mathrm{C}_{15} \mathrm{H}_{12} \mathrm{~N}_{2} \mathrm{O}_{3}: \mathrm{C}, 67.22 ; \mathrm{H}$, 4.51. Found: C, 67.16; H, 4.47.

1-(4'-Aminophenyl)-3-(3"-pyridinyl)-2-propen-1-one (13): Orange red crystals, yield $62.06 \%$, m.p. $160-163^{\circ} \mathrm{C}$. IR $\left(\mathrm{KBr}, \mathrm{v}_{\max }, \mathrm{cm}^{-1}\right): 3437,3354,1636,1595$ and $1342 .{ }^{1} \mathrm{H}$ NMR $\left(\mathrm{CDCl}_{3}, 400 \mathrm{MHz}, \delta \mathrm{ppm}\right): 4.13\left(2 \mathrm{H}\right.$, br s, $\left.\mathrm{NH}_{2}\right), 6.63(2 \mathrm{H}, \mathrm{d}$, $J=8.8 \mathrm{~Hz}, \mathrm{C}-3{ }^{\prime}$ and 5'-H), $7.26(1 \mathrm{H}, \mathrm{d}, J=8.0 \mathrm{~Hz}, \mathrm{C}-5 "-\mathrm{H})$, $7.52(1 \mathrm{H}, \mathrm{d}, J=15.6 \mathrm{~Hz}, \mathrm{CO}-\mathrm{CH}=), 7.68(1 \mathrm{H}, \mathrm{d}, J=16.0 \mathrm{~Hz}$, $\mathrm{Ar}-\mathrm{CH}=), 7.86\left(2 \mathrm{H}, \mathrm{d}, J=8.4 \mathrm{~Hz}, \mathrm{C}-2^{\prime}\right.$ and $\left.6^{\prime}-\mathrm{H}\right), 8.54-8.52$ $(1 \mathrm{H}, \mathrm{m}, \mathrm{C}-4 "-\mathrm{H}), 8.78(2 \mathrm{H}, \mathrm{d}, J=9.0 \mathrm{~Hz}, \mathrm{C}-2$ " and $6 "-\mathrm{H}) .{ }^{13} \mathrm{C}$ $\mathrm{NMR}\left(\mathrm{CDCl}_{3}, 100 \mathrm{MHz}, \delta \mathrm{ppm}\right): 185.58,154.01,150.39$, 149.93), 137.83, 134.72, 131.21, 130.98, 125.15, 124.48, 123.80 and 112.76. EI-MS, $m / z: 225\left[\{\mathrm{M}+\mathrm{H}\}^{+}\right]$. Anal. calcd. for $\mathrm{C}_{14} \mathrm{H}_{12} \mathrm{~N}_{2} \mathrm{O}$ : C, 75.06; H, 5.39. Found: C, 75.00; H, 5.35.

1-(4'-Aminophenyl)-3-(2"-pyridinyl)-2-propen-1-one (14): Light orange crystals, yield $60.88 \%$, m.p. $146-150{ }^{\circ} \mathrm{C}$. IR $\left(\mathrm{KBr}, \mathrm{v}_{\max }, \mathrm{cm}^{-1}\right)$ : 3487, 3399, 1646, 1585, 1432 and 1336. ${ }^{1} \mathrm{H} \mathrm{NMR}\left(\mathrm{CDCl}_{3}, 400 \mathrm{MHz}, \delta \mathrm{ppm}\right): 4.12\left(2 \mathrm{H}\right.$, br s, $\left.\mathrm{NH}_{2}\right)$, $6.62\left(2 \mathrm{H}, \mathrm{d}, J=8.8 \mathrm{~Hz}, \mathrm{C}-3^{\prime}\right.$ and $\left.5^{\prime}-\mathrm{H}\right), 7.22-7.19(1 \mathrm{H}, \mathrm{m}$, C-5"-H), $7.38(1 \mathrm{H}, \mathrm{d}, J=15.0 \mathrm{~Hz}, \mathrm{CO}-\mathrm{CH}=), 7.65(1 \mathrm{H}, \mathrm{m}$, C-3"-H), 7.68 (1H, d, $J=8.0 \mathrm{~Hz}, \mathrm{C}-4 "-\mathrm{H}), 7.93$ (2H, d, $J=$ $10.0 \mathrm{~Hz}, \mathrm{C}-2$ ' and 6'-H), $8.06(1 \mathrm{H}, \mathrm{d}, J=8.8 \mathrm{~Hz}, \mathrm{C}-6 "-\mathrm{H})$, $8.60(1 \mathrm{H}, \mathrm{d}, J=15.5 \mathrm{~Hz}, \mathrm{Ar}-\mathrm{CH}=)$. EI-MS, $m / z: 225\left[\{\mathrm{M}+\mathrm{H}\}^{+}\right]$. Anal. calcd. for $\mathrm{C}_{14} \mathrm{H}_{12} \mathrm{~N}_{2} \mathrm{O}$ : C, 75.06; H, 5.39. Found: C, 75.00; H, 5.35 .

1-(4'-Aminophenyl)-3-(4"'-pyridinyl)-2-propen-1-one (15): Light orange yellow crystals, yield $55.38 \%$, m.p. 172$174{ }^{\circ} \mathrm{C}$. IR $\left(\mathrm{KBr}, v_{\max }, \mathrm{cm}^{-1}\right): 3439,3334,1643,1593,1414$ and 1336. ${ }^{1} \mathrm{H} \mathrm{NMR}\left(\mathrm{CDCl}_{3}, 400 \mathrm{MHz}, \delta \mathrm{ppm}\right): 4.16(2 \mathrm{H}$, br s, $\left.\mathrm{NH}_{2}\right), 6.63\left(2 \mathrm{H}, \mathrm{d}, J=8.4 \mathrm{~Hz}, \mathrm{C}-3^{\prime}\right.$ and $\left.5^{\prime}-\mathrm{H}\right), 7.38(2 \mathrm{H}, \mathrm{d}, J=$ $18.0 \mathrm{~Hz}, \mathrm{CO}-\mathrm{CH}=$ and C-3"-H), $7.60(2 \mathrm{H}, \mathrm{d}, J=8.0 \mathrm{~Hz}, \mathrm{C}-2 "$ and 6"-H), $7.85\left(2 \mathrm{H}, \mathrm{d}, J=8.4 \mathrm{~Hz}, \mathrm{C}-2^{\prime}\right.$ and 6'-H), $8.60(2 \mathrm{H}$, d, $J=18.6 \mathrm{~Hz}, \mathrm{Ar}-\mathrm{CH}=$ and C-5"-H). EI-MS, $m / z: 224\left(\mathrm{M}^{+}\right)$. 
Anal. calcd. for $\mathrm{C}_{14} \mathrm{H}_{12} \mathrm{~N}_{2} \mathrm{O}: \mathrm{C}, 75.06 ; \mathrm{H}, 5.39$. Found: $\mathrm{C}, 75.00$; $\mathrm{H}, 5.35$.

1-(4'-Aminophenyl)-3-(2"-quinolinyl)-2-propen-1-one (16): Yellowish red crystals, yield $48.54 \%$, m.p. $162-165^{\circ} \mathrm{C}$. IR $\left(\mathrm{KBr}, \mathrm{v}_{\max }, \mathrm{cm}^{-1}\right): 3470,3357,1638,1605,1524,1357 .{ }^{1} \mathrm{H}$ NMR $\left(\mathrm{CDCl}_{3}, 400 \mathrm{MHz}, \delta \mathrm{ppm}\right): 4.15\left(2 \mathrm{H}\right.$, br s, $\left.\mathrm{NH}_{2}\right), 6.73$ $\left(2 \mathrm{H}, \mathrm{d}, J=8.0 \mathrm{~Hz}, \mathrm{C}-3^{\prime}\right.$ and $\left.5^{\prime}-\mathrm{H}\right), 7.70(1 \mathrm{H}, \mathrm{d}, J=16.4 \mathrm{~Hz}$, $\mathrm{CO}-\mathrm{CH}=), 7.93(1 \mathrm{H}, \mathrm{d}, J=16.2 \mathrm{~Hz}, \mathrm{Ar}-\mathrm{CH}=), 8.06(1 \mathrm{H}, \mathrm{d}$, $J=10.0 \mathrm{~Hz}, \mathrm{C}-2^{\prime}$ and $\left.6^{\prime}-\mathrm{H}\right), 8.40-7.61(6 \mathrm{H}, \mathrm{m}, \mathrm{Ar}-\mathrm{H}-$ quinolinyl). EI-MS, $m / z: 275\left[\{\mathrm{M}+\mathrm{H}\}^{+}\right]$. Anal. calcd. for $\mathrm{C}_{18} \mathrm{H}_{14} \mathrm{~N}_{2} \mathrm{O}$ : C, 78.90; H, 5.15. Found: C, 78.83; H, 5.10.

Pharmacology: 2-Deoxy-D-ribose was purchased from Sigma chemical Co. (St. Louis, MO, USA). 2, 2'-azinobis-3ethylbenzothiozoline-6-sulfonic acid (ABTS) was purchased from Sigma-Aldrich, Hyderabad, India. Nitroblue tetrazolium (NBT) was purchased from Sisco Research Laboratories Pvt. Ltd., Mumbai, India. L-ascorbic acid and riboflavin were purchased from Loba Chemicals, Mumbai, India. Thiobarbituric acid was purchased from BDH Chemicals, Poole, UK. All other materials and solvents used were of analytical reagent quality.

\section{Determination of superoxide scavenging activity ${ }^{21}$}

Riboflavin photo reduction method: Superoxide scavenging activity of the compounds was determined by McCord and Fridovich method, which depends on light induced superoxide generation by riboflavin and the corresponding reduction of nitrobluetetrazolium. The assay mixture contained different quantities of the compounds and ethylene diamine tetraacetic acid (6 $\mu \mathrm{M}$ containing $0.061 \mu \mathrm{M} \mathrm{NaCN})$, nitrobluetetrazolium $(50 \mu \mathrm{M})$, riboflavin $(2 \mu \mathrm{M})$ and phosphate buffer $(58 \mathrm{mM}, \mathrm{pH} 7.8)$ to give a total volume of $3 \mathrm{~mL}$. The tubes were uniformly illuminated with an incandescent light (40 w) for $15 \mathrm{~min}$ and thereafter the optical density was measured at $560 \mathrm{~nm}$. The percentage inhibition of superoxide production was evaluated by comparing the absorbance values of control and experimental tubes. The inhibitory effects of samples on the generation of superoxide anion were estimated by the equation:

$$
\text { Inhibitory ratio }=\left[\left(\mathrm{A}_{0}-\mathrm{A}_{1}\right) \times 100\right] / \mathrm{A}_{0}
$$

where, $\mathrm{A}_{0}$ is the absorbance with no addition of sample, $\mathrm{A}_{1}$ is the absorbance with addition of sample. $\mathrm{IC}_{50}$ (the concentration necessary for $50 \%$ reduction) values were calculated from the percentage of inhibition, which was calculated from the control where no test compound was added.

\section{Determination of hydroxyl radical scavenging activity ${ }^{22}$}

Deoxyribose degradation method: Hydroxyl radical scavenging activity was measured by studying the competition between deoxyribose and the compounds for the hydroxyl radical generated from the $\mathrm{Fe}^{3+}$-ascorbate-EDTA- $\mathrm{H}_{2} \mathrm{O}_{2}$ system. The hydroxyl radical attacks deoxyribose and eventually results in thiobarbituric acid reacting substances (TBARS) formation. The reaction mixture containing deoxyribose $(2.8$ $\mathrm{mM})$, ferric chloride (0.1 mM), EDTA (0.1 mM), $\mathrm{H}_{2} \mathrm{O}_{2}(1 \mathrm{mM})$, ascorbate $(0.1 \mathrm{mM})$, phosphate buffer $(20 \mathrm{mM}, \mathrm{pH} 7.4)$ and various quantities of the compounds in a final volume of $1 \mathrm{~mL}$ was incubated for $1 \mathrm{~h}$ at $37^{\circ} \mathrm{C}$. Thiobarbituric acid reacting substances method was proposed to measure deoxyribose degradation. $\mathrm{IC}_{50}$ values were calculated from the percentage of inhibition, which was calculated from the control where no test compound was added.

Determination of $\mathrm{ABTS}^{+}$radical cation scavenging activity: The $\mathrm{ABTS}^{+}$radical cation scavenging activity of test compounds, ascorbic acid (as standard) was determined according to Re et al. ${ }^{23}$. Briefly, $5 \mathrm{~mL}$ of $7.0 \mathrm{mM}$ ABTS was reacted with $88.0 \mu \mathrm{L}$ of $140 \mathrm{mM}$ potassiumpersulfate overnight in the dark to yield the $\mathrm{ABTS}^{+}$radical cation. Prior to use in the assay, the $\mathrm{ABTS}^{+}$radical cation diluted with $50 \%$ ethanol for an initial absorbance of $\approx 0.700$ (1:88 ratio) at 734 $\mathrm{nm}$, with temperature control set at $30^{\circ} \mathrm{C}$. Free radical scavenging activity was assessed by mixing $1.0 \mathrm{~mL}$ diluted $\mathrm{ABTS}^{+}$ radical cation with $10 \mu \mathrm{L}$ of test antioxidant and monitoring the change in absorbance at $0,0.5,1 \mathrm{~min}$ and again at $5 \mathrm{~min}$ intervals until a steady state was achieved. The antioxidant capacity of tested compounds were calculated and expressed as $\mathrm{IC}_{50}$.

Determination of lipid peroxidation inhibitory activity: Inhibition of lipid peroxidation was determined by the thiobarbituric acid method ${ }^{24}$. Different quantities of the compounds were incubated at $37{ }^{\circ} \mathrm{C}$ with $25 \%$ (w/v) rat liver homogenate $(0.1 \mathrm{~mL})$ containing Tris-Buffer $(40 \mathrm{mM}, \mathrm{pH} 7.0)$, $\mathrm{KCl}(30 \mathrm{mM})$, ascorbic acid $(0.06 \mathrm{mM})$ and ammonium ferrous sulphate $(0.16 \mathrm{mM})$ in a total volume of $0.5 \mathrm{~mL}$ for $1 \mathrm{~h}$. At the end of the incubation period, $0.4 \mathrm{~mL}$ of the reaction mixture was treated with $0.2 \mathrm{~mL}$ of sodium dodecyl sulphate $(8.1 \%), 1.5 \mathrm{~mL}$ thiobarbituric acid $(0.8 \%)$ and $1.5 \mathrm{~mL}$ of acetic acid (20\%, pH 3.5). The total volume was then made up to $4 \mathrm{~mL}$ by adding distilled water and kept in an oil bath at $95^{\circ} \mathrm{C}$ for $1 \mathrm{~h}$. After the mixture had been cooled, $1 \mathrm{~mL}$ of distilled water and $5 \mathrm{~mL}$ of butanol-pyridine mixture (15:1 v/v) was added. Following vigorous shaking, the tubes were centrifuged and the absorbance of the upper layer containing the chromophore was read at $532 \mathrm{~nm}$. The percentage inhibition of lipid peroxidation was determined by comparing the absorbance values of the control and experimental tubes and calculated $\mathrm{IC}_{50}$ values of all tested chalcones and standard from their percentage inhibition values.

The $\mathrm{IC}_{50}$ values of chalcones tested for their antioxidant activity against reactive oxygen species and inhibition of lipid peroxidation are shown in Table-2.

\section{RESULTS AND DISCUSSION}

Chalcones were prepared by Claisen-Schmidt condensation, starting from the reaction of 4-aminoacetophenone with various substituted aromatic and heteroaromatic aldehydes under basic conditions in the presence of alcohol to furnish 4'-aminochalcones 1 to 16, in good yield (37-81\%). A number of $\alpha, \beta$-unsaturated ketones possessed preferential reactivity towards thiols ${ }^{25}$, one of the identified mechanisms is the driving force for the present study. Chalcones possessing such $\alpha, \beta$ unsaturated carbonyl entity, capable of acting as a soft electrophile would attract only soft nucleophiles like thiols but unlikely to react with hard nucleophiles like amino and hydroxyl groups present on nucleic acids.

Antioxidant activity: The in vitro antioxidant activity and scavenging effects of the sixteen chalcones were evaluated by using different reactive oxygen species assays containing 
TABLE-2

$\mathrm{IC}_{50}$ VALUES OF 4'-AMINOCHALCONES (1 TO 16) AND ASCORBIC ACID

\begin{tabular}{|c|c|c|c|c|c|}
\hline \multirow{2}{*}{ Compound } & \multirow{2}{*}{$\mathrm{Ar}$} & \multicolumn{4}{|c|}{$\mathrm{IC}_{50}(\mu \mathrm{g} / \mathrm{mL})$} \\
\hline & & Superoxide radical $^{\mathrm{a}}$ & Hydroxyl radical $^{\mathrm{b}}$ & $\mathrm{ABTS}^{+}$cation radical ${ }^{\mathrm{c}}$ & Lipid peroxidation $^{\mathrm{d}}$ \\
\hline 1 & 3-Bromophenyl & $85.65 \pm 1.30$ & $204.33 \pm 1.53$ & $74.45 \pm 0.96$ & $600.85 \pm 2.38$ \\
\hline 2 & 4-Methylphenyl & $86.02 \pm 1.69$ & $192.15 \pm 2.18$ & $64.85 \pm 0.34$ & $587.25 \pm 2.32$ \\
\hline 3 & 2-Chlorophenyl & $88.25 \pm 1.33$ & $185.14 \pm 1.62$ & $78.86 \pm 1.56$ & $612.12 \pm 2.31$ \\
\hline 4 & 4-Chlorophenyl & $78.84 \pm 1.99$ & $170.18 \pm 1.43$ & $55.87 \pm 0.63$ & $547.57 \pm 3.50$ \\
\hline 5 & 2,4-Dichlorophenyl & $82.54 \pm 1.57$ & $207.21 \pm 1.33$ & $73.45 \pm 1.69$ & $650.32 \pm 1.54$ \\
\hline 6 & 4-Fluorophenyl & $79.73 \pm 1.58$ & $175.71 \pm 1.61$ & $61.06 \pm 1.78$ & $552.18 \pm 2.98$ \\
\hline 7 & 4-Methoxyphenyl & $80.09 \pm 1.21$ & $179.01 \pm 1.58$ & $56.91 \pm 0.68$ & $575.97 \pm 1.80$ \\
\hline 8 & 3,4-Dimethoxyphenyl & $80.65 \pm 1.58$ & $168.63 \pm 1.55$ & $52.89 \pm 1.31$ & $550.47 \pm 1.97$ \\
\hline 9 & 3,4,5-Trimethoxyphenyl & $78.32 \pm 1.59$ & $158.18 \pm 1.63$ & $50.06 \pm 1.41$ & $547.18 \pm 2.01$ \\
\hline 10 & 4-Dimethylaminophenyl & $78.87 \pm 1.32$ & $151.48 \pm 1.09$ & $50.36 \pm 1.22$ & $423.08 \pm 2.26$ \\
\hline 11 & 9-Anthracenyl & $89.25 \pm 1.99$ & $198.22 \pm 1.69$ & $76.32 \pm 2.66$ & $652.25 \pm 1.44$ \\
\hline 12 & 4-Nitrophenyl & $85.31 \pm 1.30$ & $194.22 \pm 1.76$ & $62.32 \pm 1.33$ & $612.46 \pm 2.99$ \\
\hline 13 & 3-Pyridinyl & $88.97 \pm 1.53$ & $189.63 \pm 2.18$ & $77.22 \pm 1.38$ & $617.74 \pm 2.32$ \\
\hline 15 & 4-Pyridinyl & $88.31 \pm 1.34$ & $185.21 \pm 1.35$ & $77.01 \pm 2.06$ & $624.46 \pm 1.92$ \\
\hline \multirow[t]{2}{*}{16} & 2-Quinolinyl & $88.87 \pm 1.78$ & $197.87 \pm 1.48$ & $77.98 \pm 2.52$ & $656.54 \pm 1.75$ \\
\hline & Ascorbic acid & $69.89 \pm 0.82$ & $113.50 \pm 0.91$ & $45.42 \pm 1.24$ & $488.62 \pm 1.02$ \\
\hline
\end{tabular}

All values are expressed as mean \pm SD of 3 determinations

TABLE-3

\% INHIBITION OF SUPEROXIDE RADICAL USING RIBOFLAVIN PHOTO REDUCTION METHOD

\begin{tabular}{|c|c|c|c|c|c|}
\hline \multirow{2}{*}{ Compound } & \multicolumn{5}{|c|}{ Quantity ( $\mu \mathrm{g})$} \\
\hline & 5 & 10 & 25 & 50 & 100 \\
\hline 1 & $13.23 \pm 1.25$ & $18.56 \pm 0.57$ & $25.32 \pm 1.21$ & $38.54 \pm 0.67$ & $50.89 \pm 0.52$ \\
\hline 2 & $15.70 \pm 0.23$ & $22.60 \pm 0.20$ & $30.26 \pm 1.30$ & $41.76 \pm 0.17$ & $52.87 \pm 0.12$ \\
\hline 3 & $13.21 \pm 0.54$ & $21.35 \pm 0.26$ & $27.59 \pm 1.23$ & $37.58 \pm 0.52$ & $50.01 \pm 1.32$ \\
\hline 4 & $11.76 \pm 0.34$ & $19.48 \pm 0.15$ & $29.77 \pm 0.21$ & $41.54 \pm 0.21$ & $53.30 \pm 0.53$ \\
\hline 5 & $8.69 \pm 0.18$ & $16.60 \pm 0.57$ & $26.08 \pm 0.35$ & $41.89 \pm 0.38$ & $52.17 \pm 0.23$ \\
\hline 6 & $8.98 \pm 0.35$ & $17.22 \pm 0.44$ & $28.46 \pm 0.46$ & $39.32 \pm 0.55$ & $50.93 \pm 0.47$ \\
\hline 7 & $10.25 \pm 1.02$ & $17.64 \pm 0.51$ & $29.31 \pm 0.87$ & $40.28 \pm 0.69$ & $51.05 \pm 1.05$ \\
\hline 8 & $11.19 \pm 0.33$ & $18.05 \pm 0.38$ & $29.24 \pm 0.47$ & $38.26 \pm 1.35$ & $51.98 \pm 0.53$ \\
\hline 9 & $16.72 \pm 0.23$ & $22.77 \pm 0.54$ & $34.87 \pm 0.74$ & $41.99 \pm 0.48$ & $51.60 \pm 0.69$ \\
\hline 10 & $17.46 \pm 1.11$ & $23.62 \pm 0.75$ & $35.95 \pm 0.75$ & $44.51 \pm 0.55$ & $53.08 \pm 0.59$ \\
\hline 11 & $6.58 \pm 1.04$ & $12.54 \pm 0.63$ & $25.32 \pm 078$ & $30.52 \pm 1.33$ & $40.63 \pm 0.87$ \\
\hline 12 & $16.88 \pm 0.61$ & $23.50 \pm 0.75$ & $33.44 \pm 0.63$ & $39.40 \pm 0.54$ & $53.31 \pm 0.59$ \\
\hline 13 & $7.82 \pm 053$ & $15.32 \pm 1.52$ & $30.64 \pm 054$ & $41.55 \pm 0.54$ & $51.25 \pm 0.58$ \\
\hline 15 & $8.89 \pm 0.64$ & $21.60 \pm 0.68$ & $33.47 \pm 0.63$ & $44.06 \pm 0.59$ & $52.54 \pm 0.79$ \\
\hline 16 & $7.32 \pm 0.54$ & $14.26 \pm 0.52$ & $30.25 \pm 1.03$ & $43.23 \pm 0.23$ & $51.05 \pm 0.58$ \\
\hline Ascorbic acid & $0.54 \pm 1.01$ & $0.78 \pm 0.52$ & $0.91 \pm 0.63$ & $9.32 \pm 0.21$ & $17.60 \pm 0.48$ \\
\hline
\end{tabular}

superoxide anion radical, hydroxyl radical, $\mathrm{ABTS}^{+}$cation radical and inhibition of lipid peroxidation.

Superoxide scavenging activity: All the chalcones were found to scavenge the superoxides generated by photoreduction of riboflavin, when each tested at five dose levels $(\mathbf{5}, \mathbf{1 0}, \mathbf{2 5}$, 50 and $100 \mu \mathrm{g})$. However, compounds 4, 6, 7, 9 and 10 showed a dose dependent inhibition of superoxide radicals. Ascorbic acid, the known antioxidant is employed in this study for comparing the results. Compound 9 having 3, 4, 5-trimethoxyphenyl ring was the best among all the tested chalcones. The mean values of inhibition for each compound at each concentration level are presented in Table-3.

Hydroxyl scavenging activity: Degradation of deoxyribose mediated by hydroxyl radicals generated by $\mathrm{Fe}^{3+} /$ ascorbate/ EDTA/ $/ \mathrm{H}_{2} \mathrm{O}_{2}$ system was found to be inhibited by the compounds tested. Table-4 displays the hydroxyl scavenging activity of the compounds when tested by the deoxyribose method and results are expressed as percentage inhibition of hydroxyl radical in relation to a control. All compounds in general showed good hydroxyl radical scavenging activity, when each tested at six dose levels $(\mathbf{5}, \mathbf{1 0}, \mathbf{2 5}, \mathbf{5 0}, \mathbf{1 0 0}$ and $\mathbf{2 5 0} \mu \mathrm{g})$ and in particular compounds 4, 6, 7, 8, 9 and 10 exhibited dose dependant inhibition, which is comparable to that of the standard drug ascorbic acid. Compound 10 carrying dimethylaminophenyl ring as ring B of chalcone showed highest activity.

$\mathrm{ABTS}^{+}$radical cation scavenging activity: The antioxidant ability to scavenge the $\mathrm{ABTS}^{+}$radical has been compared to the standard ascorbic acid and is an excellent tool for determining the antioxidant activity of hydrogen donating antioxidants and of chain breaking antioxidants. The percentage scavenging of $\mathrm{ABTS}^{+}$by the compounds at different concentrations were shown in Table-5. Even though all compounds showed a dose dependent scavenging activity, compounds $\mathbf{4}$, $6,7,8,9$ and 10 showed remarkable activity, comparable to 


\begin{tabular}{|c|c|c|c|c|c|c|}
\hline \multirow{3}{*}{ Compound } & \multicolumn{6}{|c|}{$\begin{array}{l}\text { TABLE-4 } \\
\text { L USING DF }\end{array}$} \\
\hline & \multicolumn{6}{|c|}{ Quantity $(\mu \mathrm{g})$} \\
\hline & 5 & 10 & 25 & 50 & 100 & 250 \\
\hline 1 & $16.31 \pm 0.65$ & $20.62 \pm 1.05$ & $28.65 \pm 0.63$ & $39.27 \pm 0.62$ & $41.23 \pm 1.21$ & $48.47 \pm 0.34$ \\
\hline 2 & $17.22 \pm 0.37$ & $23.94 \pm 0.66$ & $29.83 \pm 0.82$ & $40.33 \pm 0.57$ & $44.95 \pm 0.88$ & $50.83 \pm 0.30$ \\
\hline 3 & $15.45 \pm 0.42$ & $21.11 \pm 0.87$ & $28.47 \pm 1.63$ & $38.12 \pm 1.05$ & $40.19 \pm 0.33$ & $48.32 \pm 0.57$ \\
\hline 4 & $23.68 \pm 0.42$ & $26.84 \pm 0.52$ & $33.46 \pm 0.84$ & $36.96 \pm 0.72$ & $44.35 \pm 0.84$ & $52.52 \pm 0.46$ \\
\hline 5 & $20.24 \pm 0.92$ & $29.75 \pm 1.20$ & $33.47 \pm 1.35$ & $42.14 \pm 1.19$ & $45.46 \pm 1.23$ & $50.82 \pm 0.85$ \\
\hline 6 & $23.72 \pm 0.75$ & $28.81 \pm 0.89$ & $32.62 \pm 0.66$ & $42.37 \pm 0.47$ & $48.72 \pm 1.02$ & $53.81 \pm 0.94$ \\
\hline 7 & $24.21 \pm 0.54$ & $28.97 \pm 1.21$ & $34.55 \pm 1.45$ & $41.98 \pm 0.55$ & $48.04 \pm 0.26$ & $54.03 \pm 0.55$ \\
\hline 8 & $24.59 \pm 0.98$ & $29.83 \pm 0.81$ & $35.08 \pm 0.82$ & $42.74 \pm 0.82$ & $46.77 \pm 0.82$ & $54.42 \pm 0.62$ \\
\hline 9 & $20.67 \pm 0.81$ & $23.39 \pm 0.63$ & $35.32 \pm 0.88$ & $39.44 \pm 0.84$ & $43.57 \pm 0.80$ & $53.66 \pm 0.95$ \\
\hline 10 & $26.54 \pm 1.05$ & $34.49 \pm 1.18$ & $40.69 \pm 1.06$ & $45.34 \pm 108$ & $50.77 \pm 1.07$ & $56.02 \pm 1.04$ \\
\hline 11 & $10.47 \pm 1.21$ & $20.52 \pm 0.52$ & $29.58 \pm 2.10$ & $35.54 \pm 0.68$ & $42.97 \pm 0.64$ & $46.87 \pm 0.87$ \\
\hline 12 & $19.02 \pm 0.88$ & $28.74 \pm 0.93$ & $36.43 \pm 1.05$ & $46.96 \pm 1.47$ & $51.01 \pm 0.66$ & $52.63 \pm 0.99$ \\
\hline 13 & $10.54 \pm 1.33$ & $18.67 \pm 0.54$ & $29.31 \pm 1.55$ & $34.33 \pm 0.71$ & $41.87 \pm 0.54$ & $56.35 \pm 1.04$ \\
\hline 14 & $8.34 \pm 0.45$ & $15.56 \pm 1.72$ & $27.50 \pm 0.71$ & $33.98 \pm 0.98$ & $41.50 \pm 0.98$ & $57.31 \pm 1.26$ \\
\hline 15 & $12.68 \pm 0.86$ & $21.26 \pm 1.16$ & $31.71 \pm 1.12$ & $37.31 \pm 0.94$ & $42.53 \pm 0.93$ & $54.85 \pm 1.09$ \\
\hline 16 & $10.32 \pm 1.24$ & $15.45 \pm 1.08$ & $20.55 \pm 0.54$ & $31.11 \pm 0.52$ & $38.54 \pm 0.21$ & $49.51 \pm 1.14$ \\
\hline Ascorbic acid & $2.43 \pm 0.61$ & $3.85 \pm 1.05$ & $4.33 \pm 0.50$ & $5.22 \pm 1.52$ & $15.47 \pm 1.00$ & $42.12 \pm 2.68$ \\
\hline
\end{tabular}

\begin{tabular}{|c|c|c|c|c|c|}
\hline \multirow{3}{*}{ Compound } & \multicolumn{5}{|c|}{$\begin{array}{c}\text { TABLE-5 } \\
\text { BITION OF } \text { ABTS }^{+} \text {CATION RADICAL SCAVENGING ACTIVITY OF TEST COMPOUNDS }\end{array}$} \\
\hline & & & Quantity $(\mu \mathrm{g})$ & & \\
\hline & 5 & 10 & 25 & 50 & 100 \\
\hline 1 & $17.65 \pm 1.21$ & $20.91 \pm 0.76$ & $27.44 \pm 1.65$ & $36.15 \pm 0.45$ & $57.93 \pm 0.67$ \\
\hline 2 & $18.86 \pm 1.56$ & $22.39 \pm 1.78$ & $30.54 \pm 0.99$ & $39.24 \pm 0.44$ & $62.43 \pm 0.66$ \\
\hline 3 & $13.83 \pm 0.98$ & $18.54 \pm 1.57$ & $24.97 \pm 0.68$ & $35.24 \pm 1.26$ & $58.75 \pm 0.54$ \\
\hline 4 & $17.67 \pm 1.32$ & $20.85 \pm 0.68$ & $27.35 \pm 1.02$ & $36.56 \pm 0.78$ & $56.47 \pm 0.99$ \\
\hline 5 & $15.23 \pm 0.56$ & $18.98 \pm 0.87$ & $25.35 \pm 1.22$ & $32.32 \pm 0.58$ & $50.98 \pm 1.68$ \\
\hline 6 & $18.92 \pm 0.76$ & $22.27 \pm 1.02$ & $28.21 \pm 0.89$ & $32.26 \pm 1.25$ & $47.91 \pm 0.99$ \\
\hline 7 & $19.35 \pm 1.65$ & $23.35 \pm 0.55$ & $27.47 \pm 0.68$ & $34.24 \pm 0.43$ & $50.35 \pm 1.98$ \\
\hline 8 & $15.70 \pm 0.56$ & $19.02 \pm 0.72$ & $25.64 \pm 1.26$ & $34.48 \pm 0.38$ & $56.55 \pm 1.57$ \\
\hline 9 & $17.56 \pm 0.65$ & $21.53 \pm 1.33$ & $28.62 \pm 2.31$ & $34.84 \pm 0.58$ & $51.58 \pm 1.26$ \\
\hline 10 & $10.52 \pm 0.35$ & $12.35 \pm 1.24$ & $19.26 \pm 0.56$ & $27.02 \pm 0.65$ & $46.64 \pm 1.52$ \\
\hline 11 & $5.65 \pm 1.25$ & $14.24 \pm 0.69$ & $26.36 \pm 1.55$ & $30.21 \pm 0.57$ & $38.21 \pm 1.35$ \\
\hline 12 & $20.70 \pm 0.54$ & $25.56 \pm 1.02$ & $35.55 \pm 1.57$ & $48.73 \pm 1.21$ & $65.21 \pm 0.38$ \\
\hline 13 & $13.33 \pm 1.88$ & $16.69 \pm 0.34$ & $20.23 \pm 0.53$ & $25.54 \pm 1.39$ & $37.52 \pm 1.76$ \\
\hline 14 & $11.71 \pm 0.99$ & $17.22 \pm 1.22$ & $21.40 \pm 0.91$ & $26.87 \pm 0.67$ & $40.90 \pm 1.17$ \\
\hline 15 & $15.13 \pm 1.68$ & $17.22 \pm 2.06$ & $21.40 \pm 0.91$ & $26.97 \pm 0.78$ & $33.93 \pm 2.11$ \\
\hline 16 & $5.65 \pm 1.24$ & $15.35 \pm 1.33$ & $19.48 \pm 0.55$ & $20.14 \pm 1.11$ & $30.35 \pm 2.31$ \\
\hline Ascorbic acid & $12.35 \pm 0.59$ & $23.46 \pm 0.44$ & $27.86 \pm 0.65$ & $35.58 \pm 2.13$ & $57.53 \pm 0.78$ \\
\hline
\end{tabular}

that of the standard drug ascorbic acid. Compound $\mathbf{9}$ and $\mathbf{1 0}$ showed maximum activity.

Inhibition of lipid peroxidation: Lipid peroxides generated by the induction of $\mathrm{Fe}^{2+} /$ ascorbate on rat liver homogenate were found to be inhibited by the addition of synthesized chalcones when tested by thiobarbituric acid method, using ascorbic acid as standard. Table- 6 exhibited the percentage inhibition of lipid peroxidation of the compounds tested. Compounds 4, 6, 7, 9 and 10 showed dose dependent inhibitions when each tested at different dose levels $(50,100$, 200, 300, 500 and $750 \mu \mathrm{g}$ ). Again compound $\mathbf{9}$ and $\mathbf{1 0}$ found to be the most potent.

From the results of the antioxidant activity studies it is evident that the compound $\mathbf{9}$ and $\mathbf{1 0}$ possessed significant activity either in reactive oxygen species assays or in inhibiting the lipid peroxidation, which suggest electron releasing pharmacophores like methoxy or dimethylamino group may be essential for activity and compounds when synthesized and tested with such type of functional groups as substituent may further conform this observation. Such observation is also consistent with the earlier reports. As superoxides and peroxide radicals are inevitable participants in the process of tumor promotion $^{26}$.

It could be inferred from this study that substitution of electron donating groups at the ortho and/or para positions of the benzene ring could increase the antioxidant activity of the chalcones.

\section{REFERENCES}

1. B. Halliwell and J.M.C. Gutteridge, Free Radicals in Biology and Medicine, Oxford Clarendon Press, edn. 1, p. 279 (1985).

2. R.L. Wilson, Free Radicals and Tissue Damage, Mechanistic Evidence from Radiation Studies, In: Biochemical Mechanisms of Liver Injury. Academic Press, New York, 123, (1988).

3. S. Wang, G.J. Dusting, C.N. May and O.L. Woodman, Br. J. Pharmacol., 142, 443 (2004).

4. M.L. Go, X. Wu and X.L. Liu, Curr. Med. Chem., 12, 483 (2005). 
TABLE-6

\% INHIBITION OF LIPID PEROXIDATION USING THIOBARBITURIC ACID METHOD

\begin{tabular}{|c|c|c|c|c|c|c|}
\hline \multirow{2}{*}{ Compound } & \multicolumn{6}{|c|}{ Quantity $(\mu g)$} \\
\hline & 50 & 100 & 200 & 300 & 500 & 750 \\
\hline 1 & $15.22 \pm 0.68$ & $18.51 \pm 1.21$ & $22.34 \pm 0.65$ & $28.66 \pm 0.87$ & $39.38 \pm 1.22$ & $49.74 \pm 0.34$ \\
\hline 2 & $17.33 \pm 1.12$ & $21.37 \pm 1.37$ & $27.41 \pm 0.86$ & $32.25 \pm 0.90$ & $43.14 \pm 1.54$ & $54.43 \pm 1.41$ \\
\hline 3 & $8.66 \pm 0.57$ & $16.57 \pm 1.31$ & $20.94 \pm 0.52$ & $30.23 \pm 0.98$ & $41.05 \pm 1.22$ & $50.95 \pm 0.38$ \\
\hline 4 & $5.46 \pm 0.39$ & $15.43 \pm 0.96$ & $24.21 \pm 1.12$ & $32.42 \pm 1.13$ & $44.53 \pm 0.98$ & $54.29 \pm 1.19$ \\
\hline 5 & $10.48 \pm 0.57$ & $20.59 \pm 1.10$ & $29.21 \pm 0.92$ & $39.32 \pm 1.23$ & $45.62 \pm 1.17$ & $54.68 \pm 1.68$ \\
\hline 6 & $14.74 \pm 1.39$ & $19.92 \pm 1.21$ & $28.28 \pm 1.22$ & $43.42 \pm 1.21$ & $48.60 \pm 1.15$ & $54.97 \pm 0.85$ \\
\hline 7 & $10.58 \pm 1.64$ & $19.34 \pm 0.55$ & $28.65 \pm 0.67$ & $41.14 \pm 0.59$ & $48.24 \pm 1.11$ & $53.97 \pm 1.34$ \\
\hline 8 & $8.58 \pm 1.01$ & $19.02 \pm 0.89$ & $26.49 \pm 0.92$ & $39.17 \pm 0.89$ & $48.50 \pm 0.82$ & $54.85 \pm 1.12$ \\
\hline 9 & $18.90 \pm 0.91$ & $21.84 \pm 0.91$ & $33.19 \pm 0.92$ & $38.23 \pm 1.04$ & $48.31 \pm 0.95$ & $55.04 \pm 1.12$ \\
\hline 10 & $12.86 \pm 0.84$ & $22.07 \pm 0.72$ & $32.77 \pm 1.07$ & $39.83 \pm 0.96$ & $47.30 \pm 0.88$ & $53.94 \pm 1.18$ \\
\hline 11 & $8.65 \pm 0.57$ & $17.85 \pm 0.87$ & $22.45 \pm 0.58$ & $30.54 \pm 1.52$ & $41.21 \pm 0.22$ & $52.14 \pm 0.68$ \\
\hline 12 & $3.57 \pm 0.49$ & $19.44 \pm 0.55$ & $27.38 \pm 1.06$ & $35.71 \pm 0.82$ & $43.65 \pm 0.83$ & $55.15 \pm 1.15$ \\
\hline 13 & $5.87 \pm 0.87$ & $18.74 \pm 1.14$ & $30.28 \pm 0.67$ & $33.38 \pm 0.97$ & $40.56 \pm 0.57$ & $55.25 \pm 0.54$ \\
\hline 15 & $6.45 \pm 0.81$ & $20.27 \pm 1.09$ & $30.41 \pm 0.91$ & $34.56 \pm 1.13$ & $41.93 \pm 0.89$ & $55.75 \pm 0.94$ \\
\hline 16 & $4.25 \pm 1.32$ & $9.67 \pm 1.04$ & $19.35 \pm 0.87$ & $25.07 \pm 1.55$ & $31.32 \pm 0.74$ & $40.47 \pm 0.85$ \\
\hline Ascorbic acid & $20.46 \pm 3.70$ & $37.01 \pm 0.83$ & $51.65 \pm 0.58$ & $59.00 \pm 0.35$ & $74.33 \pm 1.73$ & $88.51 \pm 1.28$ \\
\hline
\end{tabular}

5. S. Yamamoto, E. Aizu, H. Jiang, T. Nakadate, I. Kiyoto, J.C. Wang and R. Kato, Carcinogenesis, 12, 317 (1991).

6. R. Li, G.L. Kenyon, F.E. Cohen, X. Chen, B. Gong, J.N. Dominguez, E. Davidson, G. Kurzban, R.E. Miller and E.O. Nuzman, J. Med. Chem., 38, 5031 (1995).

7. M.N. Rao, Asian J. Chem., 16, 525 (2004).

8. P.M. Sivakumar, S.K. Geethababu and D. Mukesh, Chem. Pharm. Bull., 55, 44 (2007).

9. C.T. Jalpa, B.B. Jitender, D.U. Kuldip, T.N. Yogesh, K.J. Sudhir, C.P. Christophe, E. De Clercq and K.S. Anamik, Tetrahedron Lett., 48, 8472 (2007).

10. B. Paula, A.B.F. Camila, C.L. Paulo, A.Y. Rosendo, C.F. Valdir, E.C Torres-Santos and B. Rossi-Bergmann, Bioorg. Med. Chem., 14, 1538 (2006).

11. J.R. Dimmock, N.M. Kandepu, M. Hetherington, J.W. Quail, U. Pugazhenthi, A.M. Sudom, M. Chamankhah, P. Rose, E. Pass, T.M. Allen, S. Halleran, J. Szydlowski, B. Mutus, M. Tannous, E.K. Manavathu, T.G. Myers, E.D. Clercq and J. Balzarini, J. Med. Chem., 41, 1014 (1998).

12. A.T. Dinkova-Kostova, C. Abeygunawardana and P. Talalay, J. Med. Chem., 41, 5287 (1998).

13. V. Jacob, A.B. Paula and A. Michael, Free Radic. Biol. Med., 23, 302 (1997)

14. J.F. Ballesteros, M.J. Sanz, A. Ubeda, M.A. Miranda, S. Iborra, M. Paya and M.J. Alcaraz, J. Med. Chem., 38, 2794 (1995).
15. G.S.B. Viana, M.A.M. Bandeira and F.J.A. Matos, Phytomedicine, 10, 189 (2003).

16. M. Satyanarayana, T. Priti, K.T. Brajendra, A.K. Srivastava and R. Pratap, Bioorg. Med. Chem., 12, 883 (2004).

17. M.E. Wall, M.C. Wani, M. Govindarajan, P. Abraham, H. Taylor, T.J. Hughes, J. Warner and R. Mc Givenery, J. Nat. Prod., 51, 1084 (1988).

18. T. Nikaido, T. Ohmoto, T. Nomura, T. Fukai and U. Sankawa, Chem. Pharm. Bull., 32, 4929 (1984).

19. Y.R. Prasad, A.S. Rao, S. Sridhar and R. Rambabu, Int. J. Chem. Sci., 6, 234 (2008).

20. Y.R. Prasad, A.S. Rao and R. Rambabu, Asian J. Chem., 21, 907 (2009).

21. J.M. Mc Cord and I. Fridovich, J. Biol. Chem., 244, 6049 (1969).

22. K. Elizabeth and M.N.A. Rao, Int. J. Pharmacol., 58, 237 (1990).

23. R. Re, N. Pellegrini, A. Proteggente, A. Pannala, M. Yang and C. Rice, Free Radic. Biol. Med., 26, 1231 (1999).

24. H. Ohkawa, N. Ohishi and K. Yagi, Anal. Biochem., 95, 351 (1979).

25. J.R. Dimmock, S.K. Raghavan, B.M. Logan and G.E. Bigan, Eur. J. Med. Chem., 18, 248 (1983).

26. L.T. Gordon and S.A. Weitzman, Cancer J., 6, 257 (1993). 